\title{
A QUESTION OF POWER
}

The Politics of Kilowatt-Hours

by Torgeir Kolstø Haavik, Jens Olgard Dalseth Røyrvik, Catharina Lindheim

This article builds on long-term, ongoing studies of energy efficiency governance and development projects, and reports from one recent case study of a multi-use area development combining local heating/cooling and district heating. We approach the subject matter with a particular interest for the heterogeneous, sociomaterial substances and processes at play in realising an engineering project. With a particular focus on controversies and framing, we analyse the achievements of energy efficient solutions as processes of transformation, translation and exchange. Power is relational, and successful energy efficiency lends support from careful exploi-tation of those relations, both within and across material-technological and socio-political domains. This is discussed as the politics of kilowatt-hours. The article revolves around Energeo, a Norwegian energy central developed to make buildings in the project area - restaurants, shops, offices, hotels, scenes and residential blocks - self-sustained with heat all year. This area is covered by municipal energy regulations requiring new buildings to connect to the district heating network. Therefore negotiations had to take place, and compromises had to be made particularly between the developer and the district heating company. Our study of the energy central and the controversies surrounding it reveals a heterogeneous landscape of mixed physical and social aspects in which standards and framing play important roles. We explore the processes of transformations, translations and exchanges, and argue for this approach to understand, articulate and make transparent the techno-political heterogeneity of such processes in order to facilitate better energy governance. 


\section{Introduction}

Understanding how energy efficiency works is a tedious task. Studying energy and the methods and rationales for energy efficiency will inevitably send you to many different locations that accommodate many different processes and materials in order to explain how energy efficiency works in society. You might give up on finding any baseline logic or prime mover. However, this is the best start you can get for such studies; the sooner you give up the search for one logic, or one driving force, the better, because then you can start looking for the multitude of actors and interests at stake in energy efficiency.

Our study is based on cases of energy efficiency measures and initiatives in Norway. In Norway, the usage of energy is very much related to geographical and climatic factors which make the needs vary a lot through the weeks, months and year - as well as a host of local conditions making temperatures and weather conditions very different throughout the country. Another characteristic is that in sparsely populated areas, population is often centred around cornerstone companies constituting the major local energy consumer. Many of those cornerstone companies are located where they are because of the easy access to cheap hydropower, making the efficiency of hydro-power a central political question when talking about energy efficiency in Norway. There is currently a great political will to invest in this kind of energy efficiency, as it is seen as a way to make both industry and society at large "greener" and simultaneously strengthen the economy for both local communities and industry.

Parallel to policy initiatives concerning energy efficiency, there was a clear increase in the use of the term in Norwegian publicity from 2006 and onwards'. Although the usage of the term energy efficiency has somewhat straightforward and unproblematic connotations in the public domain ${ }^{2}$, this changes when one starts looking into the details. There is no way of avoiding the details if the task is to understand the technopolitics of energy efficiency, given how deeply these details are woven into the social and material fabric that provides us with heat, cooling, light and darkness through the days and nights.

\section{Theoretical approach}

A considerable deficit of social science research on energy has been documented by Sovacool $\left(2014^{[[]]}\right)$and Sovacool et al. (2015 $\left.5^{[r]}\right)$. In an extensive literature review of publications in Energy Policy, Electricity Journal, and The Energy Journal showed over a fifteen-year period that the social sciences are grossly underrepresented. In addition,
In this article we seek to portray the phenomenon of energy efficiency as it appears in three different cases from the building and industrial sector - all typical in a Norwegian setting. In particular we explore the case of Energeo - an energy initiative that serves a multi-use area of seven buildings with local heat - situated in an area where regulations require a connection to the energy provider FarFetched's district heat network ${ }^{3}$. Our take on this is inspired by Science and Technology Studies (STS), in particular the sociology of translation and uncertainty associated with Latour (2005 $\left.5^{[r]}, 1987^{[[]}\right)$ in combination with the perspectives of framing and overflowing (Callon $1998^{[r]}$ ). The sociology of translation and the processes of framing and overflowing in energy efficiency in built environments in particular has been topicalised and made relevant by Hojem et al. $\left(2014^{[r]}\right)$ and Solli and Berker $\left(2014^{[i]}\right)$, and in general STS-related approaches to energy research have proven to be fruitful (e.g. Skjølsvold and Lindkvist 2015[r], Goulden et al. 2015 [r], Ryghaug and Sørensen 2009 $9^{[r]}$, Johansen $2012^{[[]}$, Johansen and Røyrvik $\left.2014^{[[]}\right)$.

Our aim is to bring to light the rich repertoire of the energy efficiency discourse and cut across domains of technology and politics that are often conceived as self-sustained and clearly demarcated. This repertoire is well-known piece by piece; our ambition goes further than simply listing them. The aim of the article is to explore how the different technological and political aspects of the repertoire are interwoven, and thus to portray a realm of energy efficiency that is less simplistic and more ambiguous than the straightforward appearance of kilowatt-hours may suggest. The article hence contributes to conceptualising the mechanisms of exchange between the technical-material and socio-political domains of energy efficiency.

Our aim is to think aloud on energy efficiency in ways that supplement the technological and positivist views that dominate the political and technical energy research discourses. Through conceptual exploration we follow the processes of transformations, translations and exchanges to understand the politics of energy efficiency. By theoretically supported conceptual reflections, the findings are suitable for indicating directions and orientations for further and empirically grounded research.

when social sciences do engage with energy research, they typically bring in behavioural science aspects relating to barriers and drivers for adoption, and a clear distinction between the technical and the social (Shove $1998^{[r]}$ ). The integration with physical science are very limited, such as the bringing in of meaningful references

\footnotetext{
1 The database A-tekst has registered a maximum of 132 articles per year using the search word energy efficiency (in Norwegian: energieffektivisering) in Norwegian newspapers until 2005 (before the year 2000 not more than 20), from 2007 the lowest registered number of articles is 1615 (2015), and the highest 3812 (2009).

2 As Aune et al. (2016) and Godbolt (2015) show, there is not one unified understanding of the term in the public discourse - but the term is used as if there is no conflicting understandings.

3 The name has been changed to ensure anonymity
} 
to common physical units for energy analysis (Cooper 2017 ${ }^{[\mathrm{r}]}$ ). Sovacool (2014 $\left.4^{[[]}\right)$and Sovacool et al. (2015 $\left.5^{[[]}\right)^{\prime} s$ call for interdisciplinarity should thus be seen as a call both for more social science and more relevant social science in energy research. While this is a problem related to energy research in general, Hojem et. al (2014 $\left.{ }^{[i]}\right)$ show that this is especially problematic related to the field of energy efficiency. The STS approach adopted in this article seeks to respond to both these issues. The aim is to address sociomaterial systems without factorising them in ways that conceal the very relations that are foundational to these systems.

\section{Energy efficiency and the sociology of uncertainty}

A central advice of STS is that of engaging with controversies, referring to, "situations where actors disagree" (Venturini 2010[r], 261), or as Macsopol formulates:

"...every bit of science and technology which is not yet stabilized, closed or 'black boxed'... we use it as a general term to describe shared uncertainty. (Venturini 2010[r], 260, citing Macospol)

The relationship between controversies and uncertainties is thus intimate, and Latour's $\left(2005^{[r]}, 2004^{[r]}, 1987^{[r]}\right.$, Latour and Woolgar $\left.1986^{[[]}\right)$take on STS can be conceived as a methodology for exploring controversies. Here we will highlight in particular four central tenets.

First, when referring to actors, the scope of STS is wide and includes more than social individuals and groups. Rather, agency is also ascribed to non-human entities that make a difference, and particularly so those that can be counted as mediators and not only intermediates - adding momentum and direction to courses of action that are not fully predictable (Latour 2004 $4^{[[]}$). Consequently, there may be humans or human roles that act in a fully predictable manner, and hence count as intermediaries, but not as full-blown actors. Hence, in STS there is an initial uncertainty with respect to who counts as an actor. Thus, when accounting for action in the field of energy efficiency, there is not necessarily any fundamental difference in the way we treat project leaders, kilowatt-hours, plumbers, technical standards, politicians or heat exchangers. Following the actors means also following the kilowatts circulating through the complex technical system of, let's say, an energy central.

Second, we should be aware to not take ready-made, given groups as relevant units in our enquiries. Rather, our interest is towards the different, and not always foreseeable groups that are under formation, and the processes at work to form and stabilise these groups. Thinking of the demarcation of groups in terms of networks instead of in terms of borders is useful in order to visualise groups that transcend obvious "homogeneous" groups that are more practical and swift to orient between, such as "public", "electricity companies", and "left wing politicians". Keeping in mind the first characteristic (above), non-humans are very likely to have roles in the group formation that we are interested in.

Third, accounting for the actions at work in the realm of energy efficiency, as in other enterprises that STS researchers may find themselves in the middle of, requires a readiness to travel to places not planned in advance. That "action is overtaken" (Latour 2005 $5^{[\mathrm{r}]}$ ) means that actors never act alone and hence tracing the actions means always being open to adding new actors to the list of the uncertain source of action.

Fourth, pragmatism is a valuated virtue in STS, and this is what makes us able to distinguish adequately between matters of fact and matters of concern. In the realm of energy efficiency and environmental soundness, truth is highly relational. What counts as energy efficiency and environmental friendliness depends on a range of premises that may be more or less contested, such as definitions, standards, technological alternatives, weather fluctuations, regulation, and many more.

The best way to understand the uncertain nature sociotechnical development is to engage with the associated controversies, since they form cracks through which light flows and makes visible otherwise black-boxed, uncontroversial "truths".

\section{Framing and overflowing}

There is an obvious relationship, based on the interest in controversies, between the type of uncertainty that Latour is speaking of, and that which Callon (1998 $\left.8^{[i]}\right)$ labels as hot situations. Consider his description of hot situations below with the four sources of uncertainty above:

In 'hot' situations, everything becomes controversial: the identification of intermediaries and overflows, the distribution of source and target agents, the way effects are measured. These controversies, which indicate the absence of a stabilised knowledge base, usually involve a wide variety of actors. The actual list of actors, as well as their identities, will fluctuate in the course of the controversy itself and they will put forward mutually incompatible descriptions of future world states. (Callon 1998 [r], 260)

While Latour warns against the use of fixed frames in the exploration of the controversies ${ }^{4}$, Callon offers a description of how the fluctuating frames of hot situations actually work, and occasionally overflow. "Framing", says Callon, "demarcates, in regards to the network of relationships, those which are taken into account and those which are ignored" (Callon 1998[r], 15). That frames are not given, and that they may actually leak, is a valuable guidance for exploring controversies. Actually, overflowing may be considered the rule rather than the exemption, and the framing is therefore

\footnotetext{
4 "To settle scale in advance would be to one measure and one absolute frame of reference only when it is measuring that we are after; when it is traveling from one frame to the next that we want to achieve" (Latour 2005, 186).
} 


\section{N}

NORDIC JOURNAL

of Science and Technology Studies

a very costly enterprise (Callon 1998[r], 252). This would be as true for the actors and actions taken into account by those bureaucrats formulating the terms and mandate for a distant heating system, as for those entrepreneurs developing a local heating initiative.

\section{Standards and boundary objects}

An important part of the work and costs to ensure relevance and viability of the frames - or the system definitions, including all relevant actors and processes - as the context in which the energy activities take place, is the production of fixed parameters and scales that defines which actors are relevant to the system, and how their contributions should be evaluated. Standards play a special role in such occasions, contributing to the many conventions we live by (Thevenot 2009 $9^{[r]}$, Bowker and Star 2000[r]). Although standards afford coordination better than most other means, they do so in sometimes unintuitive ways, as they may be related, not as decontextualised and inert entities guiding action in a uniform manner, but rather as boundary objects (Star and Griesemer $1989^{[r]}$ ) that allow for flexible interpretation and thus may arrange for coordination of a much larger and heterogeneous circumference.

\section{Method}

The article draws on a series of research projects that took place over a period of more than five years. In close collaboration with industry and technical research ${ }^{5}$, we have studied the realisation of energy efficiency concepts and systems. In other projects, we have focused on political frame conditions, market and consumer changes related to the so-called green shift ${ }^{6}$.

The studies have been of an explorative nature, based on extended case studies (Bernard 2017 [r]). As energy efficiency is systemic by nature, we have relied on central actors that can both function as a door opener to these systems, and allow us to continue exploring the relevant actors, documents, artefacts and relations, thus in parallel to produce the system of the study. In order to understand these cases we have sought to trace the networks of actors, political schemes, rules and regulations that come in to play when such systems are to be realised.

From these projects, two particular cases have been important for developing a background understanding that have helped frame the study highlighted in this article - the Energeo case ${ }^{7}$. The first case study - Kviamarka - is one of energy collaboration in an industrial cluster (Johansen and Røyrvik 2014 $4^{[r]}$, Johansen $2012^{[[]}$). In this cluster of heterogeneous enterprises, outputs (waste) from one production company function as an input (resource) for another so the three entities heat, cold and $\mathrm{CO}_{2}$ circulate between the different activities in the cluster in order to minimise the overall energy use and waste production. A characteristic of Kviamarka is that there is no central facilitator or coordinator for the project or its creation; it was established through a collective effort by individuals who found each other through common interests that all could be realised in a win/win fashion. Another characteristic is that the improved utilisation of energy and waste was established in a brownfield cluster, with the accompanying limitations that involves.

The second case of importance was a passive-house programme administered by Enova, a governmental agency for energy efficiency. The programme ran in the period 2010-2013 as a time-limited funding scheme in the portfolio of Enova's incentive instruments to propagate energy efficient building materials and technologies, where Enova provided economic support to rehabilitation of old and realisation of new buildings that would adhere to the Norwegian standards NS 3700 and NS 3701 for passive and low energy buildings for residential and commercial use respectively (Røyrvik et al. 2015[r]).

While we draw on experience from the above-mentioned studies, we focus on one particular case in this article: the Energeo case. This is a case that shares many characteristics with Kviamarka, but that is also distinguished from this case through significant differences. Energeo is an energy central that - in cooperation with FarFetched, the city's concessionaire of district heating serves local heat and cooling to an area with mixed activities such as hotels, schools, offices, food market hall, restaurants and bars, residential blocks and premises for cultural activities such as concerts, dance and sports. In contrast to Kviamarka, Energeo was, from the start, initiated by a single developer of urban spaces and properties, who in turn recruited developers and tenants, and coordinated the development phase, as well as the subsequent operating phase.

Our empirical findings are based on interviews, location visits and document studies including consulting reports and newspaper articles about the project. Due to its innovative character, the Energeo project drew substantial attention from politicians and the media, and this documentation represented a useful entry to the case and the discourses surrounding it. All the empirical work was undertaken by two researchers.

\footnotetext{
5 In projects headed by SINTEF Energy, we have focused on the socio-technical and socio-political dimensions of energy efficiency in industrial clusters. First in the NRC projects CREATIV and INTERACT - and now in the FME centre HighEFF.

6 This was especially true in the evaluation of the Norwegian program to promote passive houses, and now in the EU project ECHOES.

7 The name has been changed to ensure anonymity.
} 
Interviews were undertaken with key stakeholders from the development side of the project. Before the first interview with a representative from the developer, we had a guided tour in the energy central where we got a visual impression of the energy production and circulation facilities, along with a presentation of the project's history. We continued to the informant's office for a more formal interview, and thereafter continued with interviews with representatives from the consulting company and the company responsible for VVS.

The interviews were carried out in a semi-structured manner, guided partly by some broad themes and some more detailed questions prepared in advance - pertaining to the process of establishing and carrying out the project, political regulations and processes, negotiations and adjustments, technological choices and solutions, but apart from that, largely followed trajectories resulting from the informants associative reasoning. This openness was deliberate and important for our approach, allowing us to follow the historical recapitulation and the lines of reasoning as seen from our informants' perspectives. Our objective was to find out what elements and relations are made relevant to and shape the achievement of energy efficiency. In that work, we explicitly sought to restrain ourselves from thinking in socio-political and techno-material categories.

All interviews were tape recorded and transcribed shortly after arrival back in our offices. Through several rounds of interpretation - aided by an incremental and theoretically inspired coding of statements into categories that gradually got the shapes that later will be recognised as transformation, translation and exchanges - the material was arranged and discussed in a way that served to illustrate not only the techno-material - but also the socio-political - aspects of energy efficiency and kilowatt-hours. While the process of producing a meaningful account of what Energeo really is a case of surely has been an open and iterative process, in ways that bear resemblance to grounded theory (Glaser and Strauss $1967^{[(])}$), our empirical study and data interpretation were also framed by central insights from previous projects, implying special attention being paid to standards and their role in black-boxing - if not settling - energy controversies.

\section{The case of Energeo}

In earlier years, Energeo housed an iron foundry and a mechanical workshop that established by the river in 1873. After the industrial activity ended in 1968, the buildings were used for storage and craft businesses for several decades, until initiatives were made in 1999 to revitalise the area. Today, only two of the older buildings are left, integrated with the rest of the new, urban landscape (Lusiani et al. 2013 $3^{[r]}$ ).

\section{The area development}

The new Energeo area was established in 2010 in a coordinated effort to develop a brownfield area of 55,000 $\mathrm{m}^{2}$ into a self-sufficient energy area with respect to heating and cooling. With one single area developer with control of the building plot and a vision for energy supply and consumption, important framework conditions were in place to realise the plans.

The core of the energy system at Energeo is the energy central. This energy central coordinates and regulates all energy flows within the system boarders to insure that all actors get their needs covered for heating and cooling. This energy system holds four different sources of energy; surplus heat from cooling processes, solar heat, heat from geo-wells and finally, heat from an external district heating network. The energy consumers are local buildings that accommodate different activities. A schematic illustration of the energy system is presented in Figure 1.

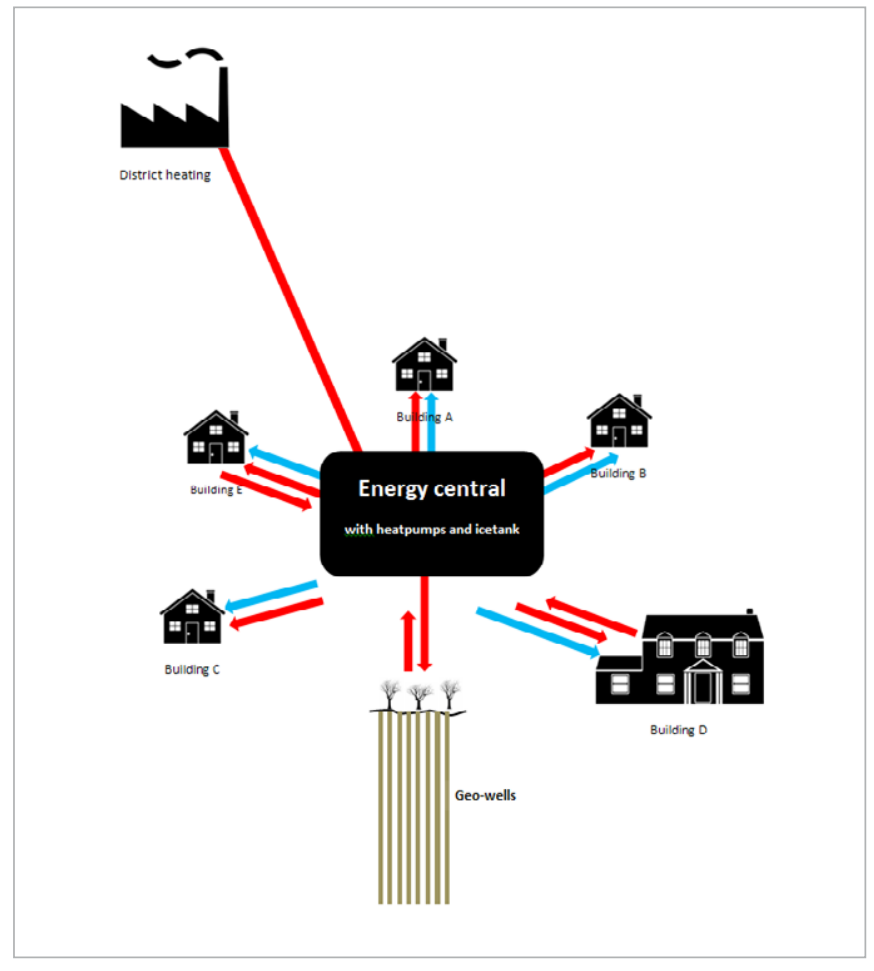

Figure 1. Schematic illustration of the Energeo energy system. 
During an iterative development process involving four steps, 64 geo-wells were drilled into the ground underneath the area. These geo-wells are mainly used as the primary energy source, where water is used as the medium to transport the heat from the ground to the energy central. During warm periods the geo-wells are also used as storage for surplus energy.

There are several buildings in the area that receive heat and cold through this energy system. The buildings house different activities (e.g. restaurants, shops, offices, hotels, scenes and residential blocks), which cause differences in the patterns of energy consumption. Most buildings only receive energy and their connections to the energy central are therefore illustrated by two arrows only: one for the receiving heat and one for the cold energy flow (cooling). Each of these arrows might as well be illustrated by a separate circle - a closed loop of heating or cooling medium exchanging heat between the building and the energy central. In this article the main interest is the flow of energy and its direction, and the arrows cover this. Other buildings, namely building $D$ and one office building, in addition to being energy consumers, also supply the energy central with heat. The office building is clad with solar collectors at the façade that faces south, gathering heat on sunny days. The heat from these collectors is delivered to the energy central for distribution as a part of the overall energy supply. In addition to being an extra source for heat production, the visibility of solar collectors - in contrast to the wells that are practically invisible - renders them as public eye-catchers. This was an added value for the environmental protection organisation that was to be the user of that particular building, also lending the whole Energeo area integrity as an environmentally friendly project. Building D accommodates around 30 restaurants, food producers and the like, where cooling and freezing is a major requirement. Cooling and freezing produces much heat, and normal practice for such enterprises is to let excess heat out in open air through dry-coolers at the roof-tops. At Energeo, the heat produced in the cooling processes is seen as an energy resource instead of a waste material. The excess heat from building $D$ is fed back into the energy central and used for heating in other buildings.

The district heating is the actor that is least integrated with the rest of the Energeo energy system. The only interconnection with the rest is through heat exchangers that transfer heat from the district heating system to the local system when there is a need for external energy supplies. There is no flow of energy from the Energeo energy system to the district heating.

The variations in energy consumption between the different buildings are not the most challenging fluctuations the energy central has to handle. What makes the system especially complicated are the 24 -hour periods of high fluctuations in external temperature during spring and autumn when the difference between night temperatures and mid-day temperature sometimes exceeds $20^{\circ} \mathrm{C}$. The peak of surplus heat from food storage is congruent with the peak of need for cooling which makes the regulation of the system even more difficult. To handle these short time fluctuations, an icetank is installed inside the energy central, which is charged (cooled down) during nights and used to handle the peaks of need for cooling flows during especially hot days. It is a simple arrangement - a container with piping filled with a cooling medium that can freeze the water that fills the open space of the container into ice. The ice-tank has the capacity to deliver rapid freezing over a few hours (200 kW), enough to cover the most critical periods during the day. During the night, the water in the ice-tank is frozen again to function as a backup the next time it is needed.

\section{The Energy Central}

The energy central (Figure 2) is located in the basement of Building D (Figure 1), where three heat pumps with a total effect of $11 \mathrm{~kW}$ and two cooling aggregates of $85 \mathrm{~kW}$ each stand for all heat and cold production for the Energeo area. The energy central delivers $3375 \mathrm{~kW}$ of heating and $1814 \mathrm{~kW}$ of cooling, and a total of $5.4 \mathrm{GWh} /$ yr. From this room all the heating and cooling flows described above are regulated. Since the first "version" of the central that was operating in 2010, the process has been subject to a number of upgrades, resulting in today's central that is almost fully automated. This automation is due to a large number of sensors that are used to continuously diagnose and adjust the system, processes that are much more aligned with the capacity and modus operandi of computers than of humans.

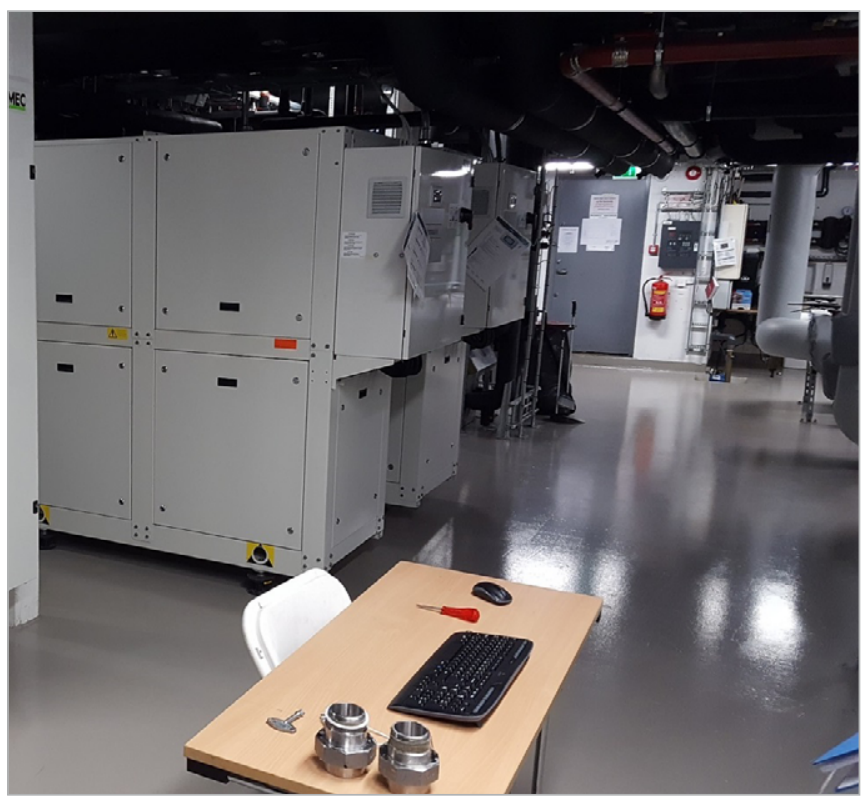

Figure 2. A view of the energy central, seen from the middle of the room. The rather sparsely equipped "work station" hints at the level of automation - necessary human intervention is reduced to a minimum.

The control system is partly a stepless one, making all the small adjustments in response to the external conditions, and a stepwise control, switching between a finite number of working modes depending on seasonal variations. 


\section{N}

NORDIC JOURNAL

of Science and Technology Studies

While Energeo may initially seem uncontroversial, providing renewable energy to the multi-use area, there are other actors, energy schemes and interests that - in the name of the same overall goal - complicate the picture. In the following, we shall see how kilowatt-hours and energy classifications are drawn into a controversy where arguments pertain as much to their associated framing of the world as to appeals to an "objective world".

\section{Controversies}

With a power efficiency of $300 \%{ }^{8}$, the heat pumps represent a power source that is competitive with most other relevant power sources. However, the situation was that a particular energy provider - FarFetched - had the licence to deliver district heating in that area, and all new building projects of certain categories within which the Energeo project was considered - were obliged to connect to this district heating network ${ }^{9}$. As a concessionaire by regulation with a monopoly on district heating - and a commercial, publicly listed company - FarFetched had the arguments and rationale necessary to dictate connection to the district heating network without further discussions or compromises. However, having rights and getting rights are not the same; right is subject to constant negotiation, and several processes pushed the balance of arguments in Energeo's direction:

As the rationale for the existence of the district heating concept and FarFetched's concession rights is grounded in environmental friendly heat, FarFetched's refusal of the local heating alternative at Energeo generated debates in the media'o that portrayed the monopoly of district heating as a barrier against new, energy friendly solutions and buildings. The argumentation was supported by a consulting report (Aamodt $2012^{[[]}$) that stated that the local energy solution project would result in a $60 \%$ reduction of energy use compared to district heating as the single heating source. The report also concluded with advice to grant exemption from the obligation to connect to the district heating network in cases where net energy supply meets the requirements of NS 3700 or NS 3701 and there is no use of fossil fuel for heating.

This report and the media debates were brought into meetings between the Plan, buildings and properties department of the municipality and FarFetched, and between the Plan, buildings and properties department and Energeo respectively. The bureaucrats faced a challenging situation with a number of arguments for the same objective - an environmental friendly energy scheme - but through different means - district heating and local heating respectively. The legitimacy of the licence regime was important both to the municipality and FarFetched, and as a result FarFetched changed its position and offered Energeo a compromise: Energeo was granted partial exemption from the district heating obligation but made a deal using district heating to secure peak load.

Requirements were also posed for the connection and subscription regime: for the Energeo area, six connection points would have to be made to the district heating network. This was counter to the solution preferred by Energeo - to have only one connection point from which they could distribute the heat to the end users.

"FarFetched used its power as a concessionaire for all it was worth, no doubt about that. They could have shown more goodwill, but they probably saw it as a threat against their deliveries." (Informant at Energeo)

According to our informant, Energeo's solution would have reduced the complexity and investment costs of the technical system. As it now became, with the six connection points, Energeo would also have to pay for six subscriptions instead of one, requiring a more expensive solution for them - and in parallel, a more economically favourable solution for FarFetched.

Another regulative requirement that affects the technical configuration of the local energy system is the requirement that limits the upper number of buildings one heat pump may provide with heat to five, to be able to be classified in energy class A. This has great significance for how buildings are classified in terms of energy efficiency, and evokes several philosophical-scientific themes such as the function of standards, and the social construction of buildings. Consider this perspective:

The regulations for energy classification of buildings are related to net energy delivered across the building border. The Energy labels spanning from $A$ to $G$ depend on $\mathrm{kWh} / \mathrm{m}^{2}$ supplied. Hence you have two extreme points: district heating produced outside the building border means that you need to provide $1 \mathrm{kWh}$ from the outside to spend $\mathrm{kWWh}$ inside, whereas if the building has its own heat pump, you need only provide $0.3 \mathrm{kWh}$. Hence, buildings with heat pumps will automatically get a better energy label than buildings using district heating. (Informant at Energeo)

When allocating energy classes to buildings, two foundational issues are of particular importance: 1) How do we measure the quantity of energy? and 2) Where do we draw the boundaries for what counts as one building? Since the answer to 1) by definition of the current classification scheme in Norway is net energy supply, buildings using heat pumps will automatically obtain a better energy classification than buildings supplied with district heat, since using $1 \mathrm{~kW}$ to run a heat pump will provide the building with

\footnotetext{
8 Efficiency of $300 \%$ undoubtedly sounds weird, and reflects the compromises between conventions and practical reality one has to deal with in order to stick to the chosen frames and standards.

9 Vedtekter til bygningsloven for Oslo by 25. mars $2009 \mathrm{nr} 433$ til \$66a https://lovdata.no/dokument/BV/forskrift/o0oo-00-00-1/KAPITTEL_8-1\#KAPITTEL_8-1

10 E.g. Teknisk Ukeblad (http://www.tu.no/artikler/her-har-de-bade-solfangere-og-geobronner-likevel-ma-de-ha-fjernvarme/236207)
} 


\section{$\$$}

NORDIC JOURNAL

of Science and Technology Studies

2.5-4 kW heat depending on the heat pump and the surrounding conditions, while the energy provided to the building from district heating still equals $1 \mathrm{~kW}$. Had one chosen to answer 1 ) by saying that the energy quantum should be measured in terms of consumption inside the buildings, then there would be no difference between heat pumps and district heat.

Given the way the regulatory regime currently relates to 1), the significance of 2) is that the more buildings that are allowed to be connected to one central heat pump that provides local heat, the more favourable it will be in terms of energy efficiency given the classification scheme. According to our informants, there is a breakpoint of 3-4 buildings, below which district heating will often be more favourable, and above which local heat pumps often will be most favourable. To ensure that district heating still can be competitive in terms of energy efficiency, a limit of 5 buildings connected to one heat pump has been established. Such an absolute number does not mean that there is no more room for negotiation, since the definition of what is a building may also leave some room for manoeuvre; anyone walking around at the Energeo area guessing where the borders around which building is drawn, may be surprised to see that this is not obvious:

This counts as one building, this as four (our informant pointing to shapes on the floor plan of Energeo). This is very complicated - what is a building? You could say that these (pointing to another shape) are four, but in terms of district heating they are seven. The conditions for that definition are hopeless! There shouldn't have been any such limits (upper limit of 5 buildings connected to one heat), the whole limit should have been removed. (Informant at Energeo)

\section{Discussion}

From the first law of thermodynamics, we learn that energy can only be transformed from one form to another, but cannot be created or destroyed. Turning from theory to practice, the aspect of transformation becomes ever more obvious, and not only that energy can be transformed from one form to another, but that it lies in the very nature of energy to transform, and that is the way energy makes a difference. In ways that will be revealed by the following discussion, the story of Energeo may be told as a story of transformation, translation and exchange of power, from the early planning phase, through the project phase and further into the operational phase.

In the energy central in the basement, five heat pumps that produce hot and cold water make up the technical backbone of the energy scheme in the operational phase. As our informants made very clear, this is a complex technical system, but it is not, in any respect, rocket science. The components and cycles are well-tried technology put into a new, site-specific constellation. Through the working of the heat pumps and the fundamental physics of temperature increase and gases being compressed, the thermal heat from the geo-wells, the solar collectors and the cooling processes is transformed into water suitable for heating the buildings at Energeo. Hot water from the district heating company is also channelled into the energy system to handle peak loads.

While the technical functioning and material appearance - of which Figure 2 provides a glimpse - of the energy system is perhaps the most striking for a visitor, one needs to also look to the socio-political aspects of the project to find the real innovation. In the following, we will elaborate on some central aspects of this, and their significance for the Energeo project.

\section{Transformations}

The energy processes at Energeo rest on a number of transformation processes, both techno-material and socio-political. While

energy resting in rock media and radiant energy from the sun is transformed into hot water through technical arrangements, these arrangements are infiltrated by extensive socio-political arrangements. Some of these are the classification schemes resulting from standardisation processes. These will be discussed under the heading of translation. Other socio-political arrangements are those resulting from negotiation processes addressing the legitimacy that is at stake when different solutions to common objectives threaten to disrepute each other. That was the case in the discourse that evolved around the controversy between the concessionaire of district heating and the local initiative of Energeo.

Since district heating works at - and is dependent on - a large scale to ensure efficiency, sustainable local energy initiatives may be perceived as both negative and positive initiatives at the same time: negative since they threaten the scaling ambition of district heating; and positive since they represent a competitive alternative to district heating in terms of price and environmental friendliness.

The discussions that took place between different constellations of the three main actors - the district heat concessionaire, the local heat developer and the local authorities - have not been possible to reconstruct or review, so the content of those is not known. What we do know, however, is that these negotiations resulted in transformation of the politics of all three parties. The outcome of that particular case illustrated a transformation that has proven to also be of a more durable character. Through the compromise that was arranged, the district heating company transformed from being an insistent concessionaire that was challenging the initiative, to being an active partner that embraces heterogeneity and enters into partnerships with former opponents. With reference to Callon's (1998 $8^{[r]}$ ) perspective on framing, one could say that from being ignored, the district heating company must now - in what can be seen as a re-framing - be taken into account. 


\section{$\$$}

NORDIC JOURNAL

of Science and Technology Studies

According to our informants, "FarFetched has changed its policy" in the wake of the Energeo project. The development of such new consolidations echoes the dynamic group formation that Latour (2005) is so concerned with. A similar movement can be observed for the developer. The development of the Energeo project started without contacting the district heat concessionaire. That frame was soon to overflow. A strategy of late involvement proved to be more challenging than necessary. They later changed their routines to include concessionaires in future projects at an early stage to negotiate agreements that benefit all parties, indicating that the re-framing process in this particular case proved to be of a more durable character

Also, the councillor for urban development, representing the municipality that once allocated the district heat company its licence as a monopolist of heat, argued later for more dispensations from the obligation to connect to the district heat, and also indicated a possible need to reformulate the regulation associated with district heating.

Although materiality and technology speak, to some extent, for themselves, they need spokespersons who can take over and reformulate the arguments of kWhs as they travel from the energy centrals in basements to other arenas such as meeting rooms, newspapers and city halls. These processes both within and between the social and the material complement our understanding of energy efficiency as a phenomenon that is far from objective and stable, but is subject to numerous transformations in order to stay efficient.

\section{Translations}

Although it is fairly easy to comprehend the meaning of energy efficiency, the way of formally accounting for it is not through perception or prose, but through standards and classifications. For the developer, energy efficiency entered into the vision for developing and marketing the area, and having an energy system that would allow for buildings to get the energy class A was important. Through the translation of a building and its energy system into Energy class $A$, the original entity and processes are being black-boxed, hiding any controversies and uncertainties. However, to understand how energy efficiency works, it is necessary to understand the context in which such translation processes take place. We particularly want to bring attention to the pragmatics of such translations.

There is an interesting tension in these translations, as they reflect the dual adoption of standards for the purpose of neutral governance (Thevenot 2009 $9^{[r]}$, Bowker and Star 2000 ${ }^{[[]}$), and the flexible use of these standards, which turns them into sometimes efficient, sometimes goal-displacing coordinating devices with characteristics resembling those of boundary objects (Star and Griesemer 1989 $9^{[r]}$, Bowker and Star 2000[r]).

The energy class is based, among other parameters, on the buildings' net energy supply. Among the entities and processes that are concealed by the classification, are the framework conditions for the calculation of the energy supply, or the convention for calculating efficiency, favouring heat pumps to district heating as described above. While it may seem strange that different conventions may provide different results, given the inescapability of the first law of thermodynamics, it gets much clearer when the difference is expressed as a difference in what we - through social negotiation processes of standardisation - establish as legitimate to include in the network" of energy forms. This illustrates the different working of conventions, such as standards in society and "laws" of nature: the working of standards in practice is far more flexible than that of "laws" in theory. While net energy supply from district heating includes in the network and the calculation the energy conserved in the combustion material producing the heat entering the buildings, net energy supply from heat pumps by convention excludes from the network and the calculation the energy extracted from the water from the geo-wells. To fully understand energy efficiency and how it looks in, for example, district and local heating in the Energeo case, it is crucial to understand the workings of these conventions in terms of their different limits of reach.

To take seriously the political aspect of the first law of thermodynamics' reference to the isolated system, for instance, is to acknowledge that an isolated system in this context represents the imperative to trace - in infinity - the energy streams and all the translations that take place through the resulting network, which is possible only in theory. While isolation and infinity are passable entities in the world of theories, they are not so in any pragmatic take on the real world. Not even inside laboratories, where the resources needed to construct and uphold the preconditions required for theories to work are substantial, and still, never safe as long as there are social constellations available to raise money for even larger laboratories (Latour and Woolgar 1986[r], Latour 1983 $\left.3^{[[]}\right)$.

The real world leaks - or as Callon would say, "overflows are the norm; framing is expensive and always imperfect" (Callon 1998[i], 252) - and we intentionally allow some leakages but not others. That is the politics of energy efficiency, in the translation processes of energy streams into classification schemes, we isolate some parts of our systems but not others; we include some energy considerations but not others. This pragmatic is a virtue of necessity for two reasons; first, since the imperative of following all energy paths in infinity would require us to constantly deal with the whole world, which is not practically possible, and second, since representing the whole world in a 1:1 fashion is the opposite

11 Network is preferred over system as a term. While system too easily brings to mind images of a geographically enclosed area that can be contained within one shape, network is a term that is better suited to imagine connected sites across the borders of many different shapes, or geographical locations. 


\section{N}

NORDIC JOURNAL

of Science and Technology Studies

of framing, and would implicate a substitution of flexible, political boundary objects that may coordinate parties with different goals and perspectives with essentialist, tyrannical theories that leaves no room for negotiation. Still, such pragmatics can only be defended if the politics that are involved in the translation processes and the resulting classification of the energy efficiency is adequately accounted for.

Furthermore, having illustrated the pragmatics of net energy supply for buildings, there is also the question of what is a building? This is brought into question as the limit of five buildings per heat pump in the energy classification scheme is reached; that is another way the politics of translations affect energy efficiency. While that limit is well defined, what counts as a building is still open for negotiation. Could complexes of connected buildings count as one building? Should one large multi-use building be considered as several buildings? These questions can stand as representatives of the politics of energy efficiency.

\section{Exchanges}

Whether an energy scheme is based on district or local heating, heat exchangers are important devices to bring the heat from its source into a usable state for the end user. Heat exchangers level out temperature differences between separate media, and they are important safety measures to build stability and decrease vulnerability. As we have seen from our case, exchanges between media are not reserved for the technical domain - remember how the travelling of kWhs between energy centrals, meeting rooms, newspapers and city halls was portrayed above. But the conditions for exchange need to be right; if the temperature difference between the hot water stream for Energeo surplus heat and the water in the district heating pipes is too large, those two systems are incompatible and cannot be connected. Compatibility is also necessary in the social sphere. In the development of Energeo, there are a few individuals that stand out as important exchangers. One is the responsible person from the consulting engineering company, who is mentioned by several informants not only as a highly skilled engineer, but also as a person with a large professional and personal network. Within this network this individual enjoys considerable trust and is mentioned as a crucial actor for making the Energeo project come into being, which can be portrayed as arranging for a framing that enjoys sufficient stability to scaffold the project in the construction phase. So if we, at this point, still believe that an energy central is held together solely by nuts and bolts, we should now hurry to add trust.

There are others as well. For not only do kWhs find their way from the energy central to the town hall, but the councillor for urban development also travels from his office and down to the energy central basement to officially open the central. Such exchanges are more than symbolic. It is from down there, in the midst of aggregates and pipes, he indicates in public a need to go through the regulations. And with the circulating speed of news, the argument soon flows over and finds its way into so many other media, expanding the frames of the now, obviously not merely technical, but techno-social - or in the STS terminology, sociomaterial - system of an energy central. So is the work of techno-social exchangers.

\section{Energy efficiency as a techno-political construct}

In addition to being a technical term, kWh articulates reality technologically (Røyrvik 2012 $2^{[r}$ ), thus aspires to belong to the realm of certainty, controlled by the rigid procedure of calculation and entification. A control founded in that reality is precisely that which is already known ${ }^{12}$, precisely known and absolutely known.

As we have seen, energy efficiency in general - and energy calculations in particular - are not already, precisely or absolutely known. The engineering communities working with rationalisation of energy know this and handle this pragmatically. In these contexts kWh refers to measured usage of energy and calculations that are conducted in order to know, predict or improve energy usage as accurately as possible.

A technologically articulated entity such as kWhs black-boxes the uncertainties and skilled considerations made by those performing and producing that articulation. When the function of $\mathrm{kWh}$ is to legitimate decisions, allocate or award money or certify buildings or systems, this is done on the basis of the numbers being objectively true and not subject to human consideration'3.

Energeo, the area as well as the energy infrastructure, has come into being by transformations, translations and exchanges; of social, technical, political and scientific processes. The system, infrastructure and even the district is hard to delineate, define and clearly separate. But who said that framing was easy? It is all about who is taken into account by a system structured around kWhs and energy classification, but calculations depend on the construction of the consuming entity and hence it may vary between types of buildings, number of buildings, production systems, system components, population and more, depending on the purpose and function of the kWh to be calculated. Therefore, the entification (Larsen 2009 $\left.{ }^{[r]}\right)$ and calculation procedures define the objects to be measured and thus controls the function that $\mathrm{kWh}$ holds relative to such political constructs as environmental certificates or energy-saving building categories, leaving us constantly wary of the collapse of tautologies (see e.g. Røyrvik et al. 2016[r], Røyrvik et al. $\left.2015^{[1]}\right)$.

Within the world of energy efficiency two different sides of the presumably standardised parameter of $\mathrm{kWh}$ give rise to settling controversies in practice. On one side uncertainties are somewhat 


\section{NORDIC JOURNAL \\ of Science and Technology Studies}

calculable, and they are pragmatically handled and operated within, and on the other side - and simultaneously - the kWhs are seen as objective and precisely representing reality. This in itself muddles the numbers, $\mathrm{kWh}$-as-indicators and $\mathrm{kWh}$-as-defined are mixed together with $\mathrm{kWh}$-as measured and $\mathrm{kWh}$-as-calculated a mixing without which they might not play the role of boundary objects as they do today. Having said that, kWh as a central parameter for Enova is currently being challenged by $\mathrm{kW}^{14}$, which may indicate that a new framing process may be in the making implying the taking into account of new actors and processes when shaping energy efficiency and viable projects in the future.

\section{Conclusion}

Power is relational. That is surely a daring statement ${ }^{15}$, considering the absoluteness expressed by first law of thermodynamics: the total energy of an isolated system is constant; energy can be transformed from one form to another, but cannot be created or destroyed. We don't have to challenge any physical laws, however, to pragmatically address their application in the real world. One important aspect that distinguishes the real world circumstances from theory is the social and political influence on events. In theory, such as in the laws of thermodynamics, the reference to isolated systems implies physical isolation to prevent energy leakages, but it also implies the isolation of any social influence on the events. The world that we live in is social and relational through and through; however, and in the pragmatics of thermodynamics, it cannot be left out of the equations.

In this study we explore presumably isolated systems, and the leakages we find are leakages that cannot be prevented, and that are not desirable to prevent either, since they permeate the merely theoretical border between the material and the social. These circumstances may be more generically referred to as framing and overflowing. Establishing and running an energy central is co-achieved by material and social actors and processes, and the stronger the requirements are for particularly effective energy configurations, the more social and political it becomes ${ }^{16}$.

Power being relational, successful energy efficiency lends support from careful exploitation of those relations, both within and across material-technological and socio-political domains. To fully understand the conditions for succeeding with energy efficiency one needs to understand the functioning of sociomaterial' networks and the framing and re-framing processes that take place within them, under the imperative of the formal and often highly standardised technical system classifications. We call this the politics of kilowatt-hours.

Our study of the energy central and the controversies surrounding it reveals a heterogeneous landscape of mixed physical and social aspects in which standards and framing play important roles. Through conceptual exploration we follow the processes of transformations, translations and exchanges to understand the politics of energy efficiency. We argue that understanding the techno-political heterogeneity of such processes, and developing ways of articulating them in ways that make them more transparent, is necessary to facilitate better energy governance.

\section{Acknowledgements}

This research has received funding from the Norwegian Research Council through the projects Interact (project nr. 228656) and HighEFF (project nr. 257632). Many thanks to two anonymous

reviewers and the editor for highly useful comments on earlier manuscript versions.

\footnotetext{
14 This may seem a minor change - merely rhetoric - but as Solli and Berker (2014) shows, the impact of rhetoric on practice should not be underestimated

15 Especially taking into account the associations that are often made between relationism and relativism. We underscore that we mean relational, however, and not relative, and refer the readers that are not familiar with the important distinction between these terms that is made in the STS literature to e.g. Latour (2004).

16 A nice illustration of this is to ask people what images come to their mind when they think of the development of river power in Norway, for example the Alta dam case (Briggs 2006). The most prominent collective memory of this is probably one of activists, politicians, policemen and the parliament building.

17 En passant: the problem of conveying sociotechnical or sociomaterial phenomena, without reducing them to a decomposable composite of social and technical/material factors, may be due to a lack of suitable or imaginable referents from our physical world - despite good and much used expressions such as imbricated, entangled or intertwined (Orlikowski 2009, Leonardi 2012, Østerlie, Almklov, and Hepsø 2012, Barad 2007). We therefore suggest that the social, technical and political aspects of sociotechnical and sociomaterial phenomena are emulsed, to draw attention towards the processes of different substances more or less irreversibly draping each other up in the same way that oil/water emulsions come into being. This also offers us an opportunity to point out nuances of the sociotechnical/-material, as - to use the same analogy - oil-in-water emulsions have different characteristics than water-in-oil emulsions.
} 


\section{References}

Aamodt, Andreas. 2012. Målkonflikter mellom energisparing og fjernvarme - problembeskrivelse og løsningsforslag (et samarbeid mellom Norsk Eiendom, EBA, Bellona, Grønn byggallianse og Norsk teknologi). Oslo: ADAPT Consulting.

Aune, Margrethe, Åsne Lund Godbolt, Knut H Sørensen, Marianne Ryghaug, Henrik Karlstrøm, and Robert Næss. 2016. "Concerned consumption. Global warming changing household domestication of energy." Energy Policy 98:290-297.

Barad, Karen. 2007. Meeting the universe halfway: quantum physics and the entanglement of matter and meaning. Durham: Duke University Press.

Bernard, Harvey Russell. 2011. Research methods in anthropology: Qualitative and quantitative approaches. Rowman Altamira.

Bowker, Geoffrey C., and Susan Leigh Star. 2000. Sorting things out: Classification and its consequences. Cambridge, MA, USA: MIT Press.

Briggs, Chad M. 2006. "Science, local knowledge and exclusionary practices: Lessons from the Alta Dam case." Norsk Geografisk Tidsskrift-Norwegian Journal of Geography 6o (2): 149-160.

Callon, Michel. 1998. The laws of the markets. Vol. 6 Oxford: Blackwell.

Cooper, Adam C.G. 2017. "Building physics into the social: Enhancing the policy impact of energy studies and energy social science research." Energy Research \& Social Science 26: 80-86.

Glaser, Barney G., and Anselm L. Strauss. 1967. The discovery of grounded theory: strategies for qualitative research. Chicago, IL, USA: Aldine.

Godbolt, Åsne Lund. 2015. "The ethos of energy efficiency: Framing consumer considerations in Norway." Energy Research \& Social Science 8:24-31.

Goulden, Shula, Evyatar Erell, Yaakov Garb, and David Pearlmutter. 2015. "Green building standards as socio-technical actors in municipal environmental policy." Building Research \& Information 45 (4): 414-425.

Heidegger, Martin, and William Lovitt. 1977. The question concerning technology, and other essays. New York: Harper \& Row.

Hojem, Thea SM, Knut H Sørensen, and Vivian A Lagesen. 2014. "Designing a 'green'building: expanding ambitions through social learning." Building Research \& Information 42 (5):591-601.

Johansen, Jens Petter, and Jens Røyrvik. 2014. "Organizing Synergies in Integrated Energy Systems." Energy Procedia 58:24-29.

Johansen, Jens Petter Kirkhus. 2012. "Konstruksjonen av et kollektivt energisystem: En kvalitativ casestudie av energisamarbeidet mellom bedriftene i Kviamarka industriklynge." Norwegian University of Science and Technology.

Larsen, Tord. 2009. "Entifisering: tingdannelsens former i vår tid." In Den globale samtalen: om dialogens muligheter, edited by Tord Larsen. Oslo: Scandinavian Academic Press.

Latour, Bruno. 1983. "Give me a laboratory and I will raise the world." In Science observed, edited by K. Knorr-Cetina and Mulkay M., 141-170. London: Sage Publications.

Latour, Bruno. 1987. Science in action: how to follow scientists and engineers through society. Milton Keynes, UK: Open University Press.

Latour, Bruno. 2004. Politics of nature: how to bring the sciences into democracy. Cambridge, MA, USA: Harvard University Press.

Latour, Bruno. 2005. Reassembling the social: An introduction to actor-network-theory, Clarendon Lectures In Management Studies. Oxford, UK: Oxford University Press.

Latour, Bruno, and Steve Woolgar. 1986. Laboratory life: the construction of scientific facts. [New ed.] Princeton, NJ, USA: Princeton University Press.

Leonardi, Paul M. 2012. "Materiality, sociomateriality, and socio-technical systems: what do these terms mean? How are they related? Do we need them?" In Materiality and organizing: Social interaction in a technological world, edited by Paul M. Leonardi, Bonnie A. Nardi, \& Jannis Kallinikos, 25-48. Oxford: Oxford University Press,

Lusiani, Maria Luca Zan, Grete Swensen, and Rikke Stenbro. 2013. "Urban planning and industrial heritage-a Norwegian case study." Journal of Cultural Heritage Management and Sustainable Development 3 (2): 175-190.

Marx, K. 1995. Kapitalen: Kritikk av den politiske økonomien. Første bok: Kapitalens produksjonsprosess. Del 1. Oslo: Forlaget Oktober A/S.

Orlikowski, Wanda J. 2009. "The sociomateriality of organisational life: considering technology in management research." Cambridge Journal of Economics 34 (1): 125-141.

Ryghaug, Marianne, and Knut H Sørensen. . 2009. "How energy efficiency fails in the building industry." Energy Policy 37 (3): 984-991.

Røyrvik, Jens, Torgeir Haavik, Kari Dalen, Jens Petter Johansen, and Jørgen K Knutsen. 2016. "Political frame conditions for energy efficiency: context sensitivity, energy flexibility and the question of scale." CIB World Building Congress, Tampere, May 30 - June 3, 2016.

Røyrvik, Jens Olgard Dalseth, Torgeir K Haavik, Gudveig Gjøsund, Jens Petter Johansen, Arne Fredrik Lånke, Heidi Ødegård Berg, Inger Andresen, and Kristian Stenerud Skeie. 2015. "Evaluering av Enovas passivhusprogram."

Røyrvik, Jens. 2012. Værvinduet: en teknologisk artikulert entitet i oljeindustriens erobring av natur (The weather window: a technologically articulated entity in the petroleum indstry's conquering of nature). Vol. 2012:368. Trondheim: Norwegian University of Science and Technology.

Shove, Elizabeth. 1998. "Gaps, barriers and conceptual chasms: theories of technology transfer and energy in buildings." Energy policy 26 (15):1105-1112.

Skjølsvold, Tomas Moe, and Carmel Lindkvist. 2015. "Ambivalence, designing users and user imaginaries in the european smart grid: insights from an interdisciplinary demonstration project." Energy Research \& Social Science 9: 43-50.

Solli, Jøran, and Thomas Berker. 2014. "Economic feasibility and 
zero emission buildings. A state-of-the-art report. " ZEB report 19 - 2014. Trondheim: SINTEF Academic Press.

Sovacool, Benjamin K. 2014. "Energy studies need social science." Nature 511 (7511): 529-530.

Sovacool, Benjamin K, S.E. Ryan, P.C. Stern, K. Janda, G. Rochlin, D. Spreng, M.J. Pasqualetti, H. Wilhite, and L. Lutzenhiser. 2015."Integrating social science in Energy research." Energy Research \& Social Science 6: 95-99.

Star, Susan Leigh, and James R. Griesemer. 1989. "Institutional ecology, 'translations'and boundary objects: amateurs and professionals in Berkeley's museum of vertebrate zoology, 1907-39." Social Studies of Science 19 (3): 387-420.

Thevenot, Laurent. 2009. "Postscript to the special issue: governing life by standards." Social Studies of Science 39: 793-813.

Venturini, Tommaso. 2010. "Diving in magma: How to explore controversies with actor-network theory." Public understanding of science 19 (3): 258-273.

Østerlie, T., Petter Grytten Almklov, and V. Hepsø. 2012. "Dual materiality and knowing in petroleum production." Information and Organization 22 (2):85-105. 